\title{
Aerodynamics of Wind Turbines
}

\author{
Emrah Kulunk \\ New Mexico Institute of Mining and Technology \\ USA
}

\section{Introduction}

A wind turbine is a device that extracts kinetic energy from the wind and converts it into mechanical energy. Therefore wind turbine power production depends on the interaction between the rotor and the wind. So the major aspects of wind turbine performance like power output and loads are determined by the aerodynamic forces generated by the wind. These can only be understood with a deep comprehension of the aerodynamics of steady state operation. Accordingly, this chapter focuses primarily on steady state aerodynamics.

\section{Aerodynamics of HAWTs}

The majority of the chapter details the classical analytical approach for the analysis of horizontal axis wind turbines and the performance prediction of these machines. The analysis of the aerodynamic behaviour of wind turbines can be started without any specific turbine design just by considering the energy extraction process. A simple model, known as actuator disc model, can be used to calculate the power output of an ideal turbine rotor and the wind thrust on the rotor. Additionally more advanced methods including momentum theory, blade element theory and finally blade element momentum (BEM) theory are introduced. BEM theory is used to determine the optimum blade shape and also to predict the performance parameters of the rotor for ideal, steady operating conditions. Blade element momentum theory combines two methods to analyze the aerodynamic performance of a wind turbine. These are momentum theory and blade-element theory which are used to outline the governing equations for the aerodynamic design and power prediction of a HAWT rotor. Momentum theory analyses the momentum balance on a rotating annular stream tube passing through a turbine and blade-element theory examines the forces generated by the aerofoil lift and drag coefficients at various sections along the blade. Combining these theories gives a series of equations that can be solved iteratively.

\subsection{Actuator Disc Model}

The analysis of the aerodynamic behaviour of wind turbines can be started without any specific turbine design just by considering the energy extraction process. The simplest model of a wind turbine is the so-called actuator disc model where the turbine is replaced by a circular disc through which the airstream flows with a velocity $U_{\infty}$ and across which there is a pressure drop from $p_{u}$ to $p_{d}$ as shown in Fig. 1. At the outset, it is important to stress that the actuator disc theory is useful in discussing overall efficiencies of turbines but 
it cannot be utilized to design the turbine blades to achieve a desired performance. Actuator disc model is based on the assumptions like no frictional drag, homogenous, incompressible, steady state fluid flow, constant pressure increment or thrust per unit area over the disk, continuity of velocity through the disk and an infinite number of blades.

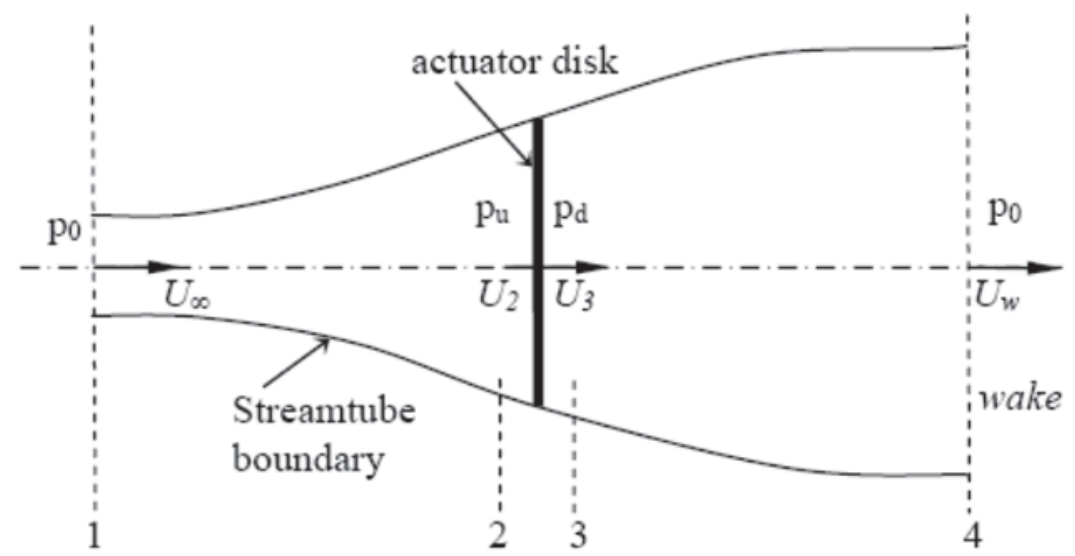

Fig. 1. Actuator Disk Model

The analysis of the actuator disk theory assumes a control volume in which the boundaries are the surface walls of a stream tube and two cross-sections. In order to analyze this control volume, four stations (1: free-stream region, 2: just before the blades, 3: just after the blades, 4: far wake region) need to be considered (Fig. 1). The mass flow rate remains the same throughout the flow. So the continuity equation along the stream tube can be written as

$$
\rho A_{\infty} U_{\infty}=\rho A_{d} U_{d}=\rho A_{w} U_{w}
$$

Assuming the continuity of velocity through the disk gives Eqn 2.

$$
\mathrm{U}_{2}=\mathrm{U}_{3}=\mathrm{U}_{\mathrm{R}}
$$

For steady state flow the mass flow rate can be obtained using Eqn 3.

$$
\dot{m}=\rho A U_{R}
$$

Applying the conservation of linear momentum equation on both sides of the actuator disk gives Eqn 4.

$$
T=\dot{m}\left(U_{\infty}-U_{w}\right)
$$

Since the flow is frictionless and there is no work or energy transfer is done, Bernoulli equation can be applied on both sides of the rotor. If we apply energy conservation using Bernoulli equation between station 1 and 2, then 3 and 4, Eqn 5 and Eqn 6 can be obtained respectively.

$$
p_{d}+\frac{1}{2} \rho U_{R}^{2}=p_{o}+\frac{1}{2} \rho U_{w}^{2}
$$




$$
p_{o}+\frac{1}{2} \rho U_{\infty}^{2}=p_{u}+\frac{1}{2} \rho U_{R}^{2}
$$

Combining Eqn 5 and 6 gives the pressure decrease $\mathrm{p}^{\prime}$ as

$$
p^{\prime}=\frac{1}{2} \rho\left(U_{\infty}^{2}-U_{w}^{2}\right)
$$

Also the thrust on the actuator disk rotor can be expressed as the sum of the forces on each side

$$
T=A p^{\prime}
$$

where

$$
p^{\prime}=\left(p_{u}-p_{d}\right)
$$

Substituting equation 7 into equation 8 gives the thrust on the disk in more explicit form.

$$
T=\frac{1}{2} A \rho\left(U_{\infty}^{2}-U_{w}^{2}\right)
$$

Combining Eqn 3, 4 and 10 the velocity through the disk can be obtained as

$$
U_{R}=\frac{U_{\infty}+U_{w}}{2}
$$

Defining the axial induction factor $\alpha$ as in Eqn 12

$$
a=\frac{U_{\infty}-U_{R}}{U_{\infty}}
$$

gives Eqn 13 and 14.

$$
\begin{gathered}
U_{R}=U_{\infty}(1-a) \\
U_{w}=U_{\infty}(1-2 a)
\end{gathered}
$$

To find the power output of the rotor Eqn 15 can be used.

$$
P=T U_{R}
$$

By substituting equation 10 into 15 gives the power output based on the momentum balance on both sides of the actuator disk rotor in more explicit form.

$$
P=\frac{1}{2} \rho\left(U_{\infty}^{2}-U_{w}^{2}\right) U_{R}
$$

Also substituting equations 13 and 14 into equation 15 gives

$$
P=2 \rho A a U_{\infty}^{3}(1-a)^{2}
$$

Finally the performance parameters of a HAWT rotor (power coefficient $C_{P}$, thrust coefficient $\mathrm{C}_{\mathrm{T}}$, and the tip-speed ratio $\lambda$ ) can be expressed in dimensionless form which is given in Eqn 18, 19 and 20 respectively. 


$$
\begin{gathered}
C_{P}=\frac{2 P}{\rho U_{\infty}^{3} \pi R^{2}} \\
C_{T}=\frac{2 T}{\rho U_{\infty}^{2} \pi R^{2}} \\
\lambda=\frac{R \Omega}{U_{\infty}}
\end{gathered}
$$

Substituting Eqn 17 into Eqn 18, the power coefficient of the rotor can be rewritten as

$$
C_{P}=4 a(1-a)^{2}
$$

Also using the equations 10,13 and 17 the axial thrust on the disk can be rewritten as

$$
T=2 A a \rho(1-a) U_{\infty}^{2}
$$

Finally substituting equation 22 into equation 19 gives the thrust coefficient of the rotor as

$$
C_{T}=4 a(1-a)
$$

\subsection{Rotating annular stream tube analysis}

Thus far the method is developed on the assumption that there was no rotational motion. To extend the method developed, the effects of this rotational motion needs to be included so it is necessary to modify the qualities of the actuator disk by assuming that it can also impart a

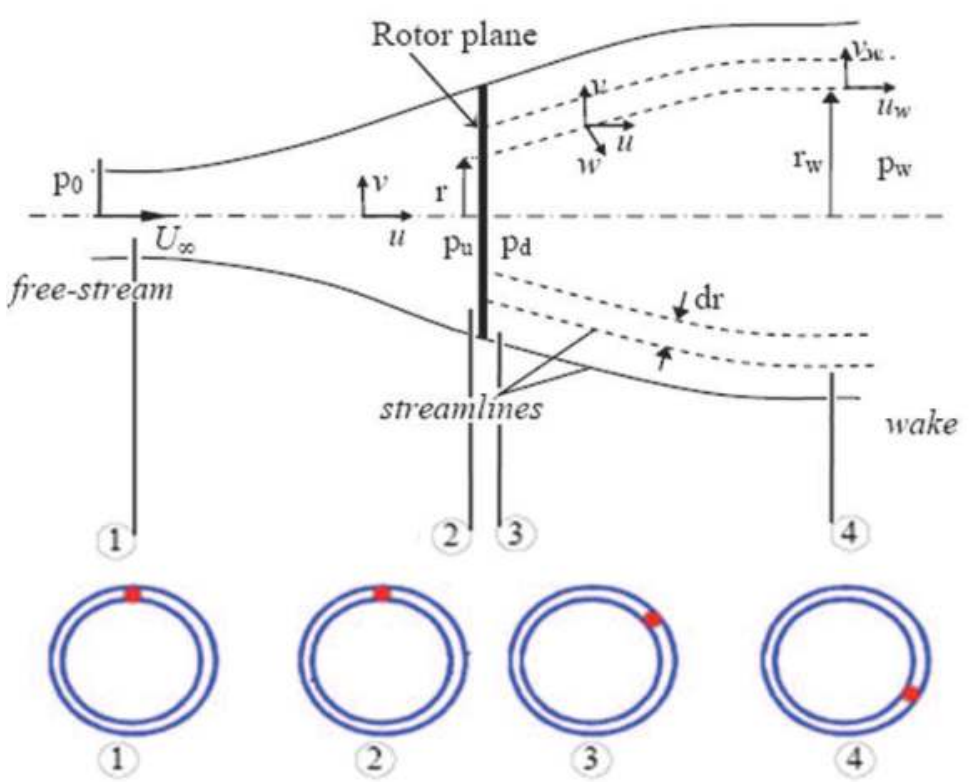

Fig. 2. Title Rotating Annular Stream Tube Analysis 
rotational component to the fluid velocity while the axial and radial components remain unchanged. Using a rotating annular stream tube analysis, equations can be written that express the relation between the wake velocities (both axial and rotational) and the corresponding wind velocities at the rotor disk.

This analysis considers the conservation of angular momentum in the annular stream tube (Fig. 2). If the condition of continuity of flow is applied for the annular element taken on the rotor plane Eqn 24 can be written.

$$
u_{w} r_{w} d r_{w}=u r d r
$$

Applying the conservation of the angular momentum on upstream and the wake region of the flow domain gives

$$
w_{w} r_{w}^{2}=w r^{2}
$$

Also the torque caused by the angular momentum balance on the differential annular element can be obtained using Eqn 26.

$$
d Q=\rho u w r^{2} d A
$$

where $d A=2 r \pi d r$. Also applying the Bernoulli equation between station 1 and 2 then between 3 and 4 gives Bernoulli's constants as

$$
\begin{gathered}
H_{o}=p_{o}+\frac{1}{2} \rho U_{\infty}^{2}=p_{u}+\frac{1}{2} \rho\left(u^{2}+v^{2}\right) \\
H_{1}=p_{d}+\frac{1}{2} \rho\left(u^{2}+v^{2}+w^{2} r^{2}\right)=p_{w}+\frac{1}{2} \rho\left(u_{w}^{2}+r_{w}^{2} w_{w}^{2}\right)
\end{gathered}
$$

And taking the difference between these constants gives

$$
H_{o}-H_{1}=p^{\prime}-\frac{1}{2} \rho\left(w^{2} r^{2}\right)
$$

Which means the kinetic energy of the rotational motion given to the fluid by the torque of the blade is equal to $-(1 / 2) \rho\left(w^{2} r^{2}\right)$. So the total pressure head between both sides of the rotor becomes

$$
\begin{aligned}
p_{o}-p_{w}=\frac{1}{2} \rho\left(u_{w}^{2}\right. & \left.-U_{\infty}^{2}\right)+\frac{1}{2} w_{w}^{2} \rho r_{w}^{2}+\left(H_{o}-H_{1}\right) \\
& =\frac{1}{2} \rho\left(u_{w}^{2}-U_{\infty}^{2}\right)+\frac{1}{2} \rho\left(w_{w}^{2} r_{w}^{2}-w^{2} r^{2}\right)+p^{\prime}
\end{aligned}
$$

Applying the Bernoulli's equation between station 2 and 3 gives the pressure drop as

$$
p^{\prime}=\frac{1}{2} \rho\left[-\Omega^{2}+(\Omega+w)^{2}\right] r^{2}=\rho\left(\Omega+\frac{w}{2}\right) w r^{2}
$$

Substituting this result into the equation 27 gives

$$
p_{o}-p_{w}=\frac{1}{2} \rho\left(u_{w}^{2}-U_{\infty}^{2}\right)+\rho\left(\Omega+\frac{w}{2}\right) r_{w}^{2} w_{w}
$$


In station 4 , the pressure gradient can be written as

$$
\frac{d p_{w}}{d r_{w}}=\rho r_{w} w_{w}^{2}
$$

Differentiating Eqn 29 relative to $r_{w}$ and equating to equation 30 gives

$$
\frac{1}{2} \frac{d}{d r_{w}}\left(U_{\infty}^{2}-u_{w}^{2}\right)=\left(\Omega+w_{w}\right) \frac{d}{d r_{w}}\left(r_{w}^{2} w_{w}\right)
$$

The equation of axial momentum for the given annular blade element in differential form can be written as

$$
d T=\rho u_{w}\left(U_{\infty}-u_{w}\right) d A_{w}+\left(p_{o}-p_{w}\right) d A_{w}
$$

Since $d T=p^{\prime} d A$, Eqn 32 can be written as Eqn 33 .

$$
d T=\rho\left(\Omega+\frac{w}{2}\right) w r^{2} d A
$$

Finally, combining Eqn 24, 27, 32 and 33 gives

$$
\frac{1}{2}\left(U_{\infty}-u_{w}\right)^{2}=\left(\frac{\Omega+w_{w} / 2}{u_{w}}-\frac{\Omega+w / 2}{U_{\infty}}\right) u_{w} r_{w}^{2} w_{w}
$$

An exact solution of the stream-tube equations can be obtained when the flow in the slipstream is not rotational except along the axis which implies that the rotational momentum $w^{2}$ has the same value for all radial elements. Defining the axial velocities as $\mathrm{u}=\mathrm{U}_{\infty}(1-\mathrm{a})$ and $\mathrm{u}_{\mathrm{w}}=\mathrm{U}_{\infty}(1-\mathrm{b})$ gives

$$
a=\frac{b}{2}\left[1-\frac{(1-a) b^{2}}{4 \lambda^{2}(b-a)}\right]
$$

Also the thrust on the differential element is equal to

$$
\begin{aligned}
d T & =2 \rho u\left(u-U_{\infty}\right) d A \\
& =4 \pi \rho U_{\infty}^{2} a(1-a) r d r
\end{aligned}
$$

Using Eqn 28 Eqn 36 can be rewritten as

$$
\begin{aligned}
d T & =p^{\prime} d A \\
& =2 \pi \rho(\Omega+w / 2) w r^{3} d r
\end{aligned}
$$

If the angular induction factor is defined as $\mathrm{a}^{\prime}=\frac{\mathrm{w}}{2 \Omega^{\prime}}$, then $\mathrm{dT}$ becomes

$$
d T=4 \pi \rho \Omega^{2} a^{\prime}\left(1+a^{\prime}\right) r^{3} d r
$$

In order to obtain a relationship between axial induction factor and angular induction factor, Eqn 37 and 38 can be equated which gives 


$$
\frac{a(1-a)}{a^{\prime}\left(1+a^{\prime}\right)}=\frac{\Omega^{2} r^{2}}{U_{\infty}^{2}}=\lambda_{r}^{2}
$$

Using Eqn 26 the torque on the differential element can be calculated as

$$
d Q=4 \pi \rho U_{\infty} \Omega a^{\prime}(1-a) r^{3} d r
$$

The power generated at each radial element is given by $\mathrm{dP}=\Omega \mathrm{dQ}$. Substituting Eqn 40 into this equation gives

$$
d P=\frac{1}{2} \rho A U_{\infty}^{3}\left[\frac{8}{\lambda^{2}} a^{\prime}(1-a) \lambda_{r}^{3} d \lambda_{r}\right]
$$

Also the power coefficient for each differential annular ring can be written as

$$
d C_{p}=\frac{d P}{1 / 2 \rho U_{\infty}^{3} A}
$$

Substituting Eqn 41 into the Eqn 42 and integrating from hub tip speed ratio to the tip speed ratio gives power coefficient for the whole rotor.

$$
C_{p}=\frac{8}{\lambda^{2}} \int_{\lambda_{h}}^{\lambda} a^{\prime}(1-a) \lambda_{r}^{3} d \lambda_{r}
$$

By solving Eqn 39 for a' in terms of a Eqn 44 can be obtained.

$$
a^{\prime}=-\frac{1}{2}+\frac{1}{2} \sqrt{1+\frac{4}{\lambda_{r}^{2}} a(1-a)}
$$

Solving the equations 43 and 44 together for the maximum possible power production gives

$$
\lambda_{r}^{2}=\frac{(1-a)(4 a-1)^{2}}{(1-3 a)}
$$

Also substituting Eqn 45 into Eqn 39 gives the angular induction factor for maximum power in each annular ring.

$$
a^{\prime}=(1-3 a) /(4 a-1)
$$

Differentiating Eqn 45 with respect to axial induction factor at rotor plane, a relationship between $\mathrm{r}, \mathrm{d} \lambda$ and da can be obtained.

$$
2 \lambda_{r} d \lambda_{r}=\left[6(4 a-1)(1-2 a)^{2} /(1-3 a)^{2}\right] d a
$$

Finally, substituting the Eqn 45, 46, 47 into the Eqn 43 gives the maximum power coefficient of the rotor

$$
C_{p, \max }=\frac{24}{\lambda^{2}} \int_{a_{1}}^{a_{2}}\left[\frac{(1-a)(1-2 a)(1-4 a)}{(1-3 a)}\right]^{2} d a
$$


Where $\mathrm{a}_{1}$ is the corresponding axial induction factor for $\lambda_{\mathrm{r}}=\lambda_{\mathrm{h}}$ and $\mathrm{a}_{2}$ is the corresponding axial induction factor for $\lambda_{\mathrm{r}}=\lambda$.

\subsection{Blade element theory}

Until this point the momentum theory is tried to be explained on account of HAWT rotor design but it does not consider the effects of rotor geometry characteristics like chord and twist distributions of the blade airfoil. For this reason blade element theory needs to be added to the design method. In order to apply blade element analysis, it is assumed that the blade is divided into $\mathrm{N}$ sections. This analysis is based on some assumptions including no aerodynamic interactions between different blade elements and the forces on the blade elements are solely determined by the lift and drag coefficients.

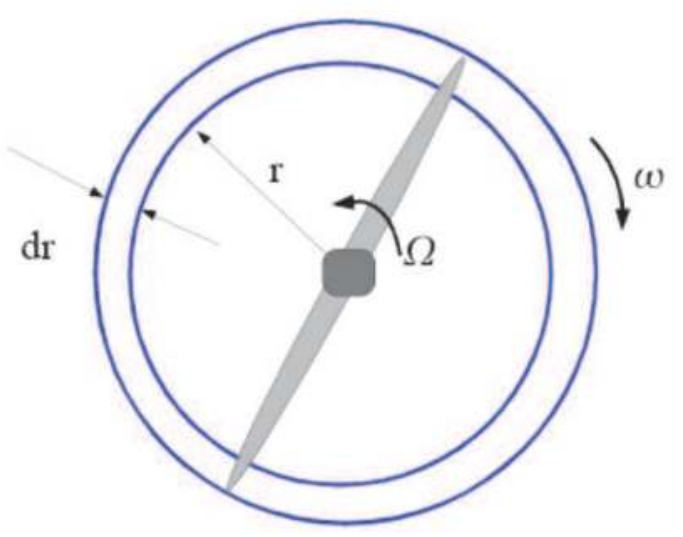

Fig. 3. Rotating Annular Stream Tube

Since each of the blade elements has a different rotational speed and geometric characteristics they will experience a slightly different flow. So blade element theory involves dividing up the blade into a sufficient number (usually between ten and twenty) of elements and calculating the flow at each one (Fig. 3, 4). Overall performance characteristics of the blade are then determined by numerical integration along the blade span.

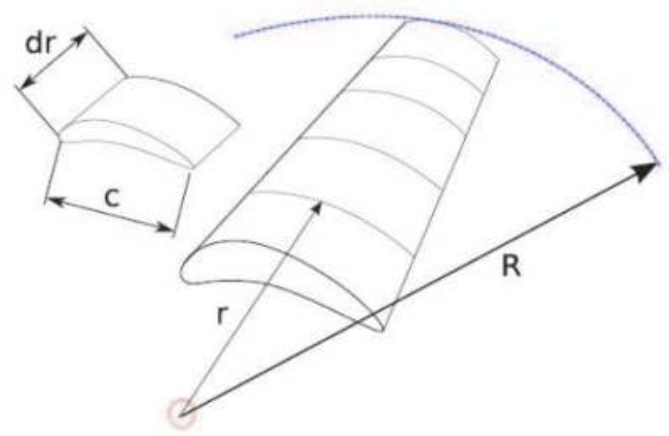

Fig. 4. The Blade Element Model 
Lift and drag coefficient data are available for a variety of airfoils from wind tunnel data. Since most wind tunnel testing is done with the aerofoil stationary, the relative velocity over the airfoil is used in order to relate the flow over the moving airfoil with the stationary test (Fig. 5).

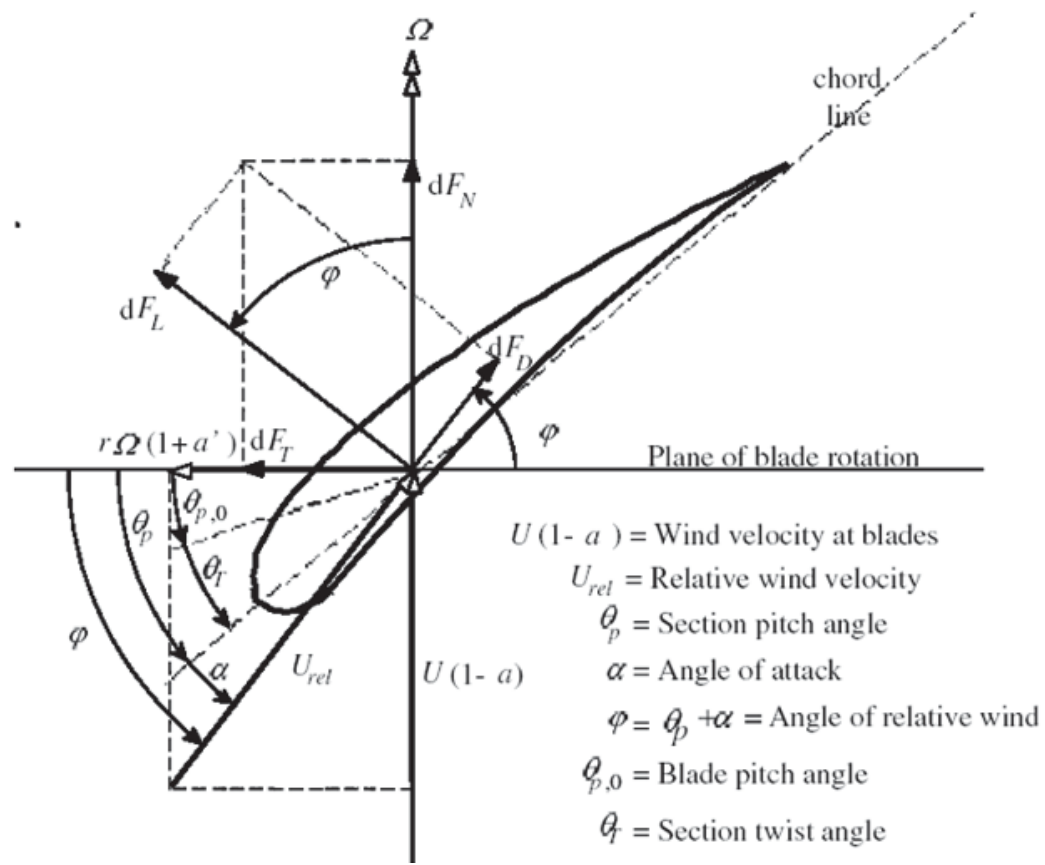

Fig. 5. Blade Geometry for the analysis of a HAWT Rotor

Examining Fig. 5, the following equations can be derived immediately.

$$
\begin{gathered}
U_{r e l}=\frac{U_{\infty}(1-a)}{\sin (\varphi)} \\
\tan (\varphi)=\frac{U_{\infty}(1-a)}{\Omega r\left(1+a^{\prime}\right)}=\frac{(1-a)}{\left(1+a^{\prime}\right) \lambda_{r}} \\
d F_{L}=C_{L} \frac{1}{2} \rho U_{r e l}^{2} c d r \\
d F_{D}=C_{D} \frac{1}{2} \rho U_{r e l}^{2} c d r \\
d L=d F_{L} \sin \varphi-d F_{D} \cos \varphi
\end{gathered}
$$




$$
d T=d F_{L} \cos \varphi+d F_{D} \sin \varphi
$$

If the rotor has B number of blades, Eqn 49, 51 and 52 can be rearranged.

$$
\begin{aligned}
& d L=B \frac{1}{2} \rho U_{r e l}^{2}\left(C_{L} \sin \varphi-C_{D} \cos \varphi\right) c d r \\
& d T=B \frac{1}{2} \rho U_{r e l}^{2}\left(C_{L} \cos \varphi+C_{D} \sin \varphi\right) c d r
\end{aligned}
$$

The elemental torque can be written as $\mathrm{dQ}=$ rdL which gives Eqn 57.

$$
d Q=B \frac{1}{2} \rho U_{r e l}^{2}\left(C_{L} \sin \varphi-C_{D} \cos \varphi\right) c r d r
$$

Also Eqn 58 can be derived by examining Fig. 5 .

$$
U_{r e l}=\frac{U_{\infty}(1-a)}{\sin \varphi}
$$

The solidity ratio can be defined as

$$
\sigma=\frac{B c}{2 \pi r}
$$

Finally, the general form of elemental torque and thrust equations becomes

$$
\begin{gathered}
d Q=\sigma \pi \rho \frac{U_{\infty}^{2}(1-a)^{2}}{\sin ^{2} \varphi}\left(C_{L} \sin \varphi-C_{D} \cos \varphi\right) r^{2} d r \\
d T=\sigma \pi \rho \frac{U_{\infty}^{2}(1-a)^{2}}{\sin ^{2} \varphi}\left(C_{L} \cos \varphi-C_{D} \sin \varphi\right) r d r
\end{gathered}
$$

Eqn 60 and Eqn 61 define the normal force (thrust) and the tangential force (torque) on annular rotor section respectively.

\subsection{Blade Element Momentum (BEM) theory}

As it is stated before BEM theory refers to the determination of a wind turbine blade performance by combining the equations of general momentum theory and blade element theory, so Eqn 36 and 61 can be equated to obtain the following expression.

$$
\frac{a}{(1-a)}=\left(\sigma C_{L}\right) \frac{\cos \varphi}{4 \sin ^{2} \varphi}\left[1+\left(C_{D} / C_{L}\right) \tan \varphi\right]
$$

Also equating Eqn 40 and 60 in the same manner gives 


$$
\frac{a^{\prime}}{(1-a)}=\frac{\left(\sigma C_{L}\right)}{4 \lambda_{r} \sin \varphi}\left[1-\left(C_{D} / C_{L}\right) \cot \varphi\right]
$$

By rearranging Eqn 63 and combining it with Eqn 50

$$
\frac{a^{\prime}}{\left(1+a^{\prime}\right)}=\frac{\left(\sigma C_{L}\right)}{4 \cos \varphi}\left[1-\left(C_{D} / C_{L}\right) \cot \varphi\right]
$$

can be written. In order to calculate the induction factors $a$ and $a^{\prime}, \mathrm{C}_{\mathrm{D}}$ can be set to zero. Thus the induction factors can be determined independently from airfoil characteristics. Subsequently, Eqn 62, 63 and 64 can be rewritten as Eqn 65, 66, and 67 respectively.

$$
\begin{gathered}
\frac{a}{(1-a)}=\left(\sigma C_{L}\right) \frac{\cos \varphi}{4 \sin ^{2} \varphi} \\
\frac{a^{\prime}}{(1-a)}=\frac{\left(\sigma C_{L}\right)}{4 \lambda_{r} \sin \varphi} \\
\frac{a^{\prime}}{\left(1+a^{\prime}\right)}=\frac{\left(\sigma C_{L}\right)}{4 \cos \varphi}
\end{gathered}
$$

Finally, by rearranging Eqn 65, 66 and 67 and solving it for $a$ and $a^{\prime}$, the following useful analytical relationships can be obtained.

$$
\begin{gathered}
a=\frac{1}{\left[1+\left[4 \sin ^{2} \varphi /\left(\sigma C_{L}\right) \cos \varphi\right]\right]} \\
a^{\prime}=\frac{1}{\left[\left[4 \cos \varphi /\left(\sigma C_{L}\right)\right]-1\right]} \\
a / a^{\prime}=\lambda_{r} / \tan \varphi \\
C_{L}=\frac{4 \sin \varphi}{\sigma} \frac{\left(\cos \varphi-\lambda_{r} \sin \varphi\right)}{\left(\sin \varphi+\lambda_{r} \cos \varphi\right)}
\end{gathered}
$$

The total power of the rotor can be calculated by integrating the power of each differential annular element from the radius of the hub to the radius of the rotor.

$$
P=\int_{n}^{R} d P=\int_{n_{n}}^{R} \Omega d Q
$$

And rewriting the power coefficient given in Eqn 18 using Eqn 72 gives 


$$
C_{p}=\frac{P}{1 / 2 \rho U_{\infty}^{3} A}=\frac{\int_{n}^{R} \Omega d Q}{1 / 2 \rho U_{\infty}^{3} \pi R^{2}}
$$

Using Eqn 60, 65 and 70 the power coefficient relation can be rearranged as

$$
C_{p}=\frac{8}{\lambda^{2}} \int_{\lambda_{h}}^{\lambda} \lambda_{r}^{3} a^{\prime}(1-a)\left[1-\left(C_{D} / C_{L}\right) \cot \varphi\right] d \lambda_{r}
$$

\subsubsection{Tip losses}

At the tip of the turbine blade losses are introduced. The ratio of the average value of tip loss factor to that at a blade position is given in Fig. 6. As it is shown in the figure only near the tip the ratio begins to fall to zero so it is called 'the tip-loss factor'.

With uniform circulation the azimuthal average value of $a$ is also radially uniform but that implies a discontinuity of axial velocity at the wake boundary with a corresponding discontinuity in pressure. Whereas such discontinuities are acceptable in the idealized actuator disc situation they will not occur in practice with a finite number of blades.

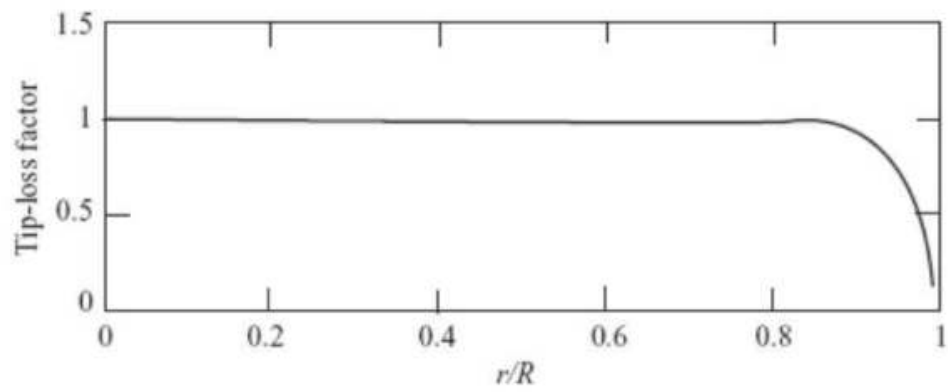

Fig. 6. Span-wise Variation of the Tip-loss Factor for a Blade with Uniform Circulation

The losses at the blade tips can be accounted for in BEM theory by means of a correction factor, $\mathrm{f}$ which varies from 0 to 1 and characterizes the reduction in forces along the blade. An approximate method of estimating the effect of tip losses has been given by L. Prandtl and the expression obtained by Prandtl for tip-loss factor is given by Eqn 74 .

$$
f=\frac{2}{\pi} \cos ^{-1}\left\{\exp \left[\frac{-(B / 2)\left[1-\left(\frac{r}{R}\right)\right]}{\left(\frac{r}{R}\right) \sin \varphi}\right]\right\}
$$

The application of this equation for the losses at the blade tips is to provide an approximate correction to the system of equations for predicting rotor performance and blade design. Carrying the tip-loss factor through the calculations, the changes will be as following:

$$
\begin{gathered}
d Q=4 f \pi \rho U_{\infty} \Omega a^{\prime}(1-a) r^{3} d r \\
d T=4 f \pi \rho U_{\infty}^{2} a(1-a) r d r
\end{gathered}
$$




$$
\begin{gathered}
\frac{a^{\prime}}{1-a}=\frac{\sigma C_{L}}{4 f \lambda_{r \sin \varphi}} \\
\frac{a^{\prime}}{1-a^{\prime}}=\frac{\sigma C_{L}}{4 f \cos \varphi} \\
C_{L}=\frac{4 f \sin \varphi}{\sigma} \frac{\left(\cos \varphi-\lambda_{r \sin \varphi}\right)}{\left(\sin \varphi+\lambda_{r \cos \varphi}\right)} \\
a=\frac{1}{1+\left[\frac{4 f \sin ^{2} \varphi}{\left(\sigma C_{L}\right) \cos \varphi}\right]} \\
a_{P}=\frac{1}{\left[\frac{4 f \cos \varphi}{\left(\sigma C_{L}\right)}-1\right]} \\
\int_{\lambda_{h}}^{\lambda} f \lambda_{r}^{3} a^{\prime}(1-a)\left[1-\frac{C_{D}}{C_{L}} \tan \beta\right] d \lambda_{r}
\end{gathered}
$$

The results for the span-wise variation of power extraction in the presence of tip-loss for a blade with uniform circulation on a three-bladed HAWT operating at a tip speed ratio of 6 is shown in Fig. 7 and it clearly demonstrates the effects of tip-loss.

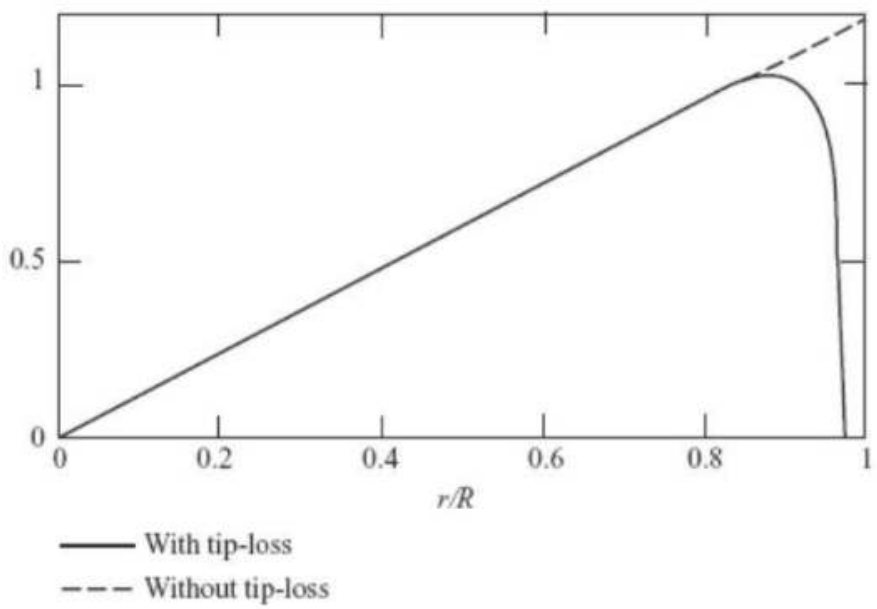

Fig. 7. Span-wise Variation of Power Extraction

Accordingly, for a selected airfoil type and a specified tip-speed ratio with blade length, the blade geometry can be designed for optimum rotor. And using these geometric parameters determined the aerodynamic performance of the rotor can be analyzed. 


\subsection{Blade design procedure}

The aerodynamic design of optimum rotor blades from a known airfoil type means determining the geometric parameters (such as chord length and twist angle distribution along the blade span) for a certain tip-speed ratio at which the power coefficient of the rotor is maximum. For this reason firstly the change of the power coefficient of the rotor with respect to tip-speed ratio should be figured out in order to determine the design tip-speed ratio $\lambda_{d}$ where the rotor has a maximum power coefficient. The blade design parameters will then be according to this design tip-speed ratio. Examining the plots between relative wind angle and local tip-speed ratio for a wide range of glide ratios gives us a unique relationship when the maximum elemental power coefficient is considered. And this relationship can be found to be nearly independent of glide ratio and tip-loss factor. Therefore a general relationship can be obtained between optimum relative wind angle and local tip-speed ratio which will be applicable for any airfoil type.

$$
\frac{\partial}{\partial \varphi}\left\{\sin ^{2} \varphi\left(\cos \varphi-\lambda_{r} \sin \varphi\right)\left(\sin \varphi+\lambda_{r} \cos \varphi\right)\right\}=0
$$

Eqn 85 reveals after some algebra;

$$
\varphi_{\text {opt }}=(2 / 3) \tan ^{-1}\left(1 / \lambda_{r}\right)
$$

Having found the solution of determining the optimum relative wind angle for a certain local tip-speed ratio, the rest is nothing but to apply the equations from 80 to 83 derived from the blade-element momentum theory and modified including the tip loss factor. Dividing the blade length into $\mathrm{N}$ elements, the local tip-speed ratio for each blade element can then be calculated as

$$
\lambda_{r, i}=\lambda\left(r_{i} / R\right)
$$

Then rewriting Eqn 86 for each blade element gives

$$
\varphi_{\text {opt }, i}=(2 / 3) \tan ^{-1}\left(1 / \lambda_{r, i}\right)
$$

In addition the tip loss correction factor for each element can be calculated as

$$
f_{i}=\frac{2}{\pi} \cos ^{-1}\left\{\exp \left[\frac{-(B / 2)\left[1-\left(\frac{r_{i}}{R}\right)\right]}{\left(\frac{r_{i}}{R}\right) \sin \varphi_{o p t, i}}\right]\right\}
$$

The local chord-length for each blade element can then be determined using the following expression

$$
c_{i}=\frac{8 \pi r_{i} F_{i} \sin \varphi_{o p t, i}}{B C_{L, \text { design }}} \frac{\left(\cos \varphi_{o p t, i}-\lambda_{r, i} \sin \varphi_{o p t, i}\right)}{\left(\sin \varphi_{o p t, i}+\lambda_{r, i} \cos \varphi_{o p t, i}\right)}
$$

where $\mathrm{C}_{\mathrm{L}_{\text {design }}}$ is chosen such that the glide ratio is minimum at each blade element. Also the twist distribution can easily be calculated by Eqn 91

$$
\theta_{i}=\varphi_{o p t, i}-\alpha_{\text {design }}
$$


where $\alpha_{\text {design }}$ is again the design angle of attack at which $\mathrm{C}_{\mathrm{L}_{\mathrm{design}}}$ is obtained. Now chordlength and twist distribution along the blade span are known and in this case lift coefficient and angle of attack have to be determined from the known blade geometry parameters. This requires an iterative solution in which for each blade element the axial and angular induction factors are firstly taken as the values equal to the corresponding designed blade elements. Then the actual induction factors are determined within an acceptable tolerance of the previous guesses during iteration.

\section{Conclusion}

The kinetic energy extracted from the wind is influenced by the geometry of the rotor blades. Determining the aerodynamically optimum blade shape, or the best possible approximation to it, is one of the main tasks of the wind turbine designer. Accordingly this chapter sets out the basis of the aerodynamics of HAWTs and the design methods based on these theories to find the best possible design compromise for the geometric shape of the rotor which can only be achieved in an iterative process.

Performance analysis of HAWT rotors has been performed using several methods. In between these methods BEM model is mainly employed as a tool of performance analysis due to its simplicity and readily implementation. Most wind turbine design codes are based on this method. Accordingly the chapter explains the aerodynamics of HAWTs based on a step-by-step approach starting from the simple actuator disk model to more complicated and accurate BEM method.

The basic of BEM method assumes that the blade can be analyzed as a number of independent elements in span-wise direction. The induced velocity at each element is determined by performing the momentum balance for an annular control volume containing the blade element. Then the aerodynamic forces on each element are calculated using the lift and drag coefficient from the empirical two-dimensional wind tunnel test data at the geometric angle of attack of the blade element relative to the local flow velocity. BEM theory-based methods have aspects by reasonable tool for designer, but they are not suitable for accurate estimation of the wake effects, the complex flow such as three-dimensional flow or dynamic stall because of the assumptions being made.

\section{Acknowledgment}

I would like to express my deepest gratitude and appreciation to Dr. Sidney Xue and Dr. Carsten H. Westengaard from VESTAS Americas R\&D Center in Houston, TX and Matthew F. Barone from Sandia National Labs Albuquerque, NM; also to Dr. Nilay Sezer Uzol from TOBB University of Economics and Technology, Ankara, Turkey and my advisors at New Mexico Tech Mechanical Engineering Department Dr. Warren J. Ostergren and Dr. Sayavur I. Bakhtiyarov for their unwavering support, invaluable guidance and encouragement throughout my formation in wind energy field.

Finally I would like to dedicate this chapter to Rachel A. Hawthorne. Thank you for all the love and happiness you have brought into my life!

\section{Nomenclature}

A: Area of wind turbine rotor

a: Axial induction factor at rotor plane $\mathrm{r}$ : Radial coordinate at rotor plane

$\mathrm{r}_{\mathrm{i}}$ : Blade radius for the ith blade element 
a': Angular induction factor

B: Number of blades of a rotor

$\mathrm{C}_{\mathrm{D}}$ : Drag coefficient of an airfoil

$\mathrm{C}_{\mathrm{L}}$ : Lift coefficient of an airfoil

$\mathrm{C}_{\mathrm{P}}$ : Power coefficient of wind turbine rotor

$\mathrm{C}_{\mathrm{T}}$ : Thrust coefficient of wind turbine rotor

$\mathrm{C}_{\mathrm{T}_{\mathrm{r}}}$ :Local thrust coefficient of each annular $\lambda_{\mathrm{d}}$ : Design tip-speed ratio rotor section

$\mathrm{c}_{\mathrm{i}}$ : Blade chord length for the ith blade element

$\mathrm{F}_{\mathrm{D}}$ : Drag force on an annular blade element

$\mathrm{F}_{\mathrm{L}}$ : Lift force on an annular blade element

$\mathrm{f}$ : Tip-loss factor

$\mathrm{f}_{\mathrm{i}}$ : Tip-loss factor for the ith blade element

$\mathrm{H}$ : Bernoulli's constant

$\dot{\mathrm{m}}$ : Air mass flow rate through rotor plane

$\mathrm{N}$ : Number of blade elements

P: Power output from wind turbine rotor

$\mathrm{p}^{\prime}$ : Pressure drop across rotor plane

Q: rotor torque

R: Radius of wind turbine rotor
T: rotor thrust

$\mathrm{U}_{\infty}$ : Free stream velocity of wind

$\mathrm{U}_{\mathrm{rel}}$ : Relative wind velocity

$\mathrm{U}_{\mathrm{R}}$ : Uniform wind velocity at rotor plane

$\alpha$ : Angle of attack

$\lambda$ : Tip-speed ratio of rotor $\lambda_{\mathrm{r}}$ : Local tip-speed ratio

$\lambda_{\mathrm{r}, \mathrm{i}}$ : Local tip-speed ratio for the ith blade element

$\theta_{\mathrm{i}}$ : Pitch angle for the ith blade element

$\varphi_{\text {opt,i }}$ : Optimum relative wind angle for the ith blade element

$\rho$ : Air density

$\Omega:$ Angular velocity of wind turbine rotor

$\sigma:$ Solidity ratio

$\mathrm{v}$ : Kinematic viscosity of air

$\gamma$ : Glide ratio

Re: Reynolds number

HAWT: Horizontal-axis wind turbine

BEM: Blade element momentum

\section{References}

Bertagnolio, F., Niels Sorensen, N., Johansen, J., Fuglsang, P., Wind Turbine Airfoil Catalogue. Riso National Laboratory, Roskilde, 2001.

Burton, T. and Sharpe, D., Wind Energy Handbook. John Wiley \& Sons Ltd, ISBN 0-471-489972, Chichester, 2006.

Glauert, H., (1935b). Windmills and Fans. Aerodynamic theory (ed. Durand, W. F.). Julius Springer, Berlin, Germany.

Hau, E., Wind Turbines: Fundamentals, Technologies, Application, Economics. Krailling, Springer, 2006.

Hoerner, S. F., (1965). 'Pressure drag on rotating bodies'. Fluid dynamic drag (ed. Hoerner, Hunt, B. R. and Lipsman, R. L., A Guide to MATLAB: For Beginners and Experienced Users. Cambridge University Press, New York, 2001.

Kulunk, E., Yilmaz, N., HAWT Rotor Design and Performance Analysis. ASME 3rd International Conference on Energy Sustainability, ES2009-90441. San Francisco, CA, USA. July 19-23, 2009.

Mathews, J. H. and Fink, K. D., Numerical Methods Using MATLAB. Prentice Hall, Upper Saddle River, 1999.

Meijer Drees, J., (1949). A theory of airflow through rotors and its application to some helicopter problems'. J. Heli. Ass. G.B., 3, 2, 79-104. S. F.), pp. 3-14.

Uzol, N., Long, L., 3-D Time-Accurate CFD Simulations of Wind Turbine Rotor Flow Fields. AIAA 2006-0394. The Pennsylvania State University, 2006.

Wilson, R. E., Lissaman, P. B. S., Walker, S. N., “Aerodynamic Performance of Wind Turbines". Energy Research and Development Administration, 224, 1976. 


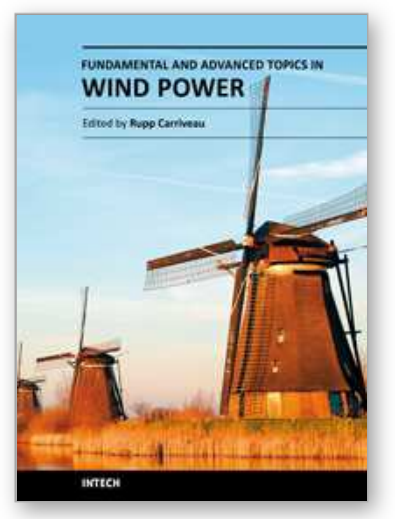

\author{
Fundamental and Advanced Topics in Wind Power \\ Edited by Dr. Rupp Carriveau
}

ISBN 978-953-307-508-2

Hard cover, 422 pages

Publisher InTech

Published online 20, June, 2011

Published in print edition June, 2011

As the fastest growing source of energy in the world, wind has a very important role to play in the global energy mix. This text covers a spectrum of leading edge topics critical to the rapidly evolving wind power industry. The reader is introduced to the fundamentals of wind energy aerodynamics; then essential structural, mechanical, and electrical subjects are discussed. The book is composed of three sections that include the Aerodynamics and Environmental Loading of Wind Turbines, Structural and Electromechanical Elements of Wind Power Conversion, and Wind Turbine Control and System Integration. In addition to the fundamental rudiments illustrated, the reader will be exposed to specialized applied and advanced topics including magnetic suspension bearing systems, structural health monitoring, and the optimized integration of wind power into micro and smart grids.

\title{
How to reference
}

In order to correctly reference this scholarly work, feel free to copy and paste the following:

Emrah Kulunk (2011). Aerodynamics of Wind Turbines, Fundamental and Advanced Topics in Wind Power, Dr. Rupp Carriveau (Ed.), ISBN: 978-953-307-508-2, InTech, Available from:

http://www.intechopen.com/books/fundamental-and-advanced-topics-in-wind-power/aerodynamics-of-windturbines

\section{INTECH}

open science | open minds

\author{
InTech Europe \\ University Campus STeP Ri \\ Slavka Krautzeka 83/A \\ 51000 Rijeka, Croatia \\ Phone: +385 (51) 770447 \\ Fax: +385 (51) 686166 \\ www.intechopen.com
}

\author{
InTech China \\ Unit 405, Office Block, Hotel Equatorial Shanghai \\ No.65, Yan An Road (West), Shanghai, 200040, China \\ 中国上海市延安西路65号上海国际贵都大饭店办公楼 405 单元 \\ Phone: +86-21-62489820 \\ Fax: +86-21-62489821
}


(C) 2011 The Author(s). Licensee IntechOpen. This chapter is distributed under the terms of the Creative Commons Attribution-NonCommercialShareAlike-3.0 License, which permits use, distribution and reproduction for non-commercial purposes, provided the original is properly cited and derivative works building on this content are distributed under the same license. 